\title{
CDISC SDTM Skin Classification Terminology
}

National Cancer Institute

\section{Source}

National Cancer Institute. CDISC SDTM Skin Classification Terminology. NCI Thesaurus.

Code C76351.

Terminology codelist used for Skin Classification within the Clinical Data Interchange

Standards Consortium Study Data Tabulation Model. 